UDK: 811.111'373.611:81'367.622

\title{
MORFOLOŠKA STRUKTURA IZVEDENIH ATRIBUTIVNIH IMENICA I SEMANTIČKI ODNOSI SA UPRAVNOM RIJEČJU IMENIČKE SINTAGME U SAVREMENOM ENGLESKOM JEZIKU
}

\author{
MAJA M. ŽARKOVIĆ ${ }^{1}$ \\ Univerzitet u Istočnom Sarajevu, \\ Filozofski fakultet, Katedra za anglistiku, \\ Pale, Bosna i Hercegovina
}

Izvedene imenice nastaju dodavanjem derivacionih nastavaka na imenice, pridjeve i glagole. Poznato je da derivacioni nastavci značenje imenice usmjeravaju ka već određenim semantičkim šablonima. Vodeći se poznatom činjenicom da atributivne imenice ekonomično ubacuju poruku u strukturu sitagme, ali da nije uvijek lako interpretirati tu poruku, osnovni cilj rada jeste vidjeti koliko morfološka struktura izvedenih atributivnih imenica ima uticaj na usmjeravanje i, na kraju, na interpretiranje dobijene poruke. Nakon deskriptivno-analitičke analize primjera sintagmi preuzetih iz novinskog registra zaključujemo da izvedene imenice ostvaruju najrazličitije semantičke odnose sa upravnom riječju sintagme i da morfološka struktura nema prevelik uticaj na usmjeravanje i, na kraju, na interpretiranje tih odnosa. Neki od odnosa mogu da se predvide na osnovu derivacionih nastavaka koji su upotrebljeni jer uvijek dovode do istih značenja sintagme, ali u velikom broju slučajeva isti nastavak nije dovodio do nastajanja istog značenja, što je samo potvrdilo već poznatu činjenicu da je interpretiranje sintagme sa atributivnim imenicama delikatno.

Ključne riječi: imenica, imenička sintagma, morfološka klasifikacija, semantički odnosi.

\section{UVOD}

Jedna od najznačajnijih metoda za bogaćenje rječnika engleskog jezika jeste derivacija odnosno dodavanje derivacionih nastavaka na već postojeće riječi kako bi nastale nove (Baugh/Cable 2002: 304). U fokusu našeg interesovanja u radu se nalaze imenice nastale kao rezultat procesa derivacije, tj. imenice nastale dodavanjem

1 Kontakt podaci (Email): maja.zarkov@gmail.com 
derivacionih nastavaka na već postojeće imenice, pridjeve i glagole. ${ }^{2}$ Kako derivacioni nastavci usmjeravaju značenje izvedene imenice ka već određenom semantičkom šablonu (na primjer, nastavak -ity se obično pronalazi kod imenica koje označavaju kvalitet, stanje ili neka druga svojstva, nastavak -ess se koristi za izvođenje imenica ženskog roda, itd. (Plag 2003: 113-115)), željeli smo da istražimo, kao osnovni cilj u radu, koliko to može biti od pomoći prilikom razumijevanja sintagme sa izvedenom atributivnom imenicom i da li uopšte postoji veza između forme atributa (u našem slučaju izvedene imenice) i značenja sintagme.

Imenice se generalno smatraju djelotvornim mehanizmima za ubacivanje dodatnih poruka u strukturu imeničke sintagme, pri čemu se ekonomično ostvaruju značenja (Biber et al. 1999) koja bi, na primjer u srpskom jeziku, zahtjevala čitavu rečenicu. Ova ekonomičnost ponekad, neminovno, dovodi do višeznačnosti, a samim tim i do poteškoća koje moraju da se savladaju da bi se poruka takvih sintagmi mogla interpretirati na pravilan način. Morfološka klasifikacija imenica dijeli imenice u tri grupe: proste, složene i izvedene imenice (Blaganja/Konte 1979: 40). Iako su i proste i složene imenice zanimljive za analizu, u radu smo se samo koncentrisali na izvedene. Naša početna hipoteza jeste da izvedene atributivne imenice ostvaruju najrazličitija značenja sa upravnom riječju sintagme, od kojih neka možemo lakše da otkrijemo zahvaljujući derivacionim nastavcima i njihovim semantičkim odlikama, ali, kao i kod svih atributivnih imenica, ponekad čak ni isti nastavci ne mogu bez konteksta da nam odmah ukažu na jedno određeno značenje.

\section{MOGUĆE SEMANTIČKE VEZE IZMEĐU UPRAVNE RIJEČI I ATRIBUTIVNE IMENICE}

Atributivne imenice i upravna riječ ostvaruju širok spektar logičnih veza. Te veze govore o različitim odnosima koji se formiraju, a od kojih su najznačajniji (Biber et al. 1999: 590-591; Жарковић 2012: 329-330)3: sadržaj (upravna riječ se sastoji od atributivne imenice ili se njome bavi), svrha (upravna riječ služi ili se koristi u svrhu atributivne imenice), identitet (upravna riječ se odnosi na isti pojam kao i atributivna imenica, ali dodaje još jedan pojam već postojećem), objekatski tip 1 (atributivna imenica je objekat u procesu koji je predstavljen upravnom riječju), objekatski tip 2 (upravna riječ je objekat u procesu koji predstavlja atributivna imenica), subjekatski tip 1 (atributivna imenica je subjekat procesa koji predstavlja upravna riječ), subjekatski tip 2 (upravna riječ je subjekat procesa koji predstavlja atributivna imenica), vrijeme (značenje upravne riječi može da se pronađe samo u vremenskom intervalu koji

2 U radu ćemo se baviti samo izvedenim imenicama nastalim kao rezultat dodavanja različitih sufiksa, ali ne i prefiksa. Mnogi autori smatraju da prefiksi, u veoma malom broju slučajeva, dovode do promjene osnove na koju se dodaju dok je to kod sufiksa često što ih ponekad čini interesantijim za analizu (Bauer 1983; Jovanović 2008). Mi nismo isključili prefikse iz analize zato što ih smatramo manje interesantnim nego samo zbog činjenice da bi detaljna analiza imenica nastalih dodavanjem i prefiksa izašla, po svom obimu, iz okvira ovog rada.

3 Veze koje ćemo koristiti za analizu naših primjera predstavljaju modifikovanu listu koju je predložio Bajber sa saradnicima u Longman Grammar of Written and Spoken English (1999). Zašto se prvobitna lista morala modifikovati, a na koji način se to uradilo pogledati Жарковић (2012). 
je predstavljen atributivnom imenicom), lokacijski tip 1 (značenje upravne riječi se odvija ili potiče sa mjesta koje je predstavljeno atributivnom imenicom), lokacijski tip 2 (značenje atributivne imenice se vezuje za mjesto koje je predstavljeno upravnom riječju), institucija (upravna riječ daje institucijske okvire atributivnoj imenici), dio (upravna riječ određuje dio atributivne imenice) i specijalizacija (atributivna imenica određuje specijalističku oblast za osobu ili zanimanje te osobe koja je predstavljena upravnom riječju; zato je upravna riječ uvijek živo biće).

Širok spektar veza koji smo predstavili, opet, ne objašnjava značenje svih imeničkih sintagmi u engleskom jeziku koje imaju imenicu kao atribut jer ponekad sintagme ne samo da svojim značenjem mogu da ostvare dva ili više pomenutih značenja nego mogu da imaju i značenje koje se ne može pronaći na pomenutoj listi. Značenje takvih sintagmi može da se shvati kada se uzme u obzir kontekst, a i kroz parafraziranje (Biber et al. 1999: 591).

\section{ANALIZA KORPUSA}

Korpus u radu predstavljali su primjeri imeničke sintagme sa izvedenim imenicama kao atributima koji su se pojavili u engleskom novinskom registru od aprila do jula 2010. godine. Korpus je prikupljen iz sljedećih dnevnih novina: The Times, The Guardian, The New York Times ${ }^{4}$. Termin registar se odnosi na jezičke razlike čije karakteristične leksičkogramatičke osobine zavise od situacije u kojoj se upotrebljavaju (Biber 2006: 11). Upravo zato glavni razlog zašto smo odabrali novinski registar jeste činjenica da se u njemu, između ostalog, na prvo mjesto stavlja potreba da se kaže što više, ali što sažetije. Takva potreba najbolje se ilustruje upotrebom atributa, u našem slučaju imenica u toj funkciji, što dovodi do nastajanja mnogobrojnih primjera. Primjere smo preuzimali iz članaka koji su objavljeni u sekciji Vijesti (News). Primjere smo pronalazili među 1781920 riječi, što je ukupan broj riječi u sakupljenim člancima. Sintagme u kojima se pojavljivala ista upravna riječ i ista izvedena imenica kao atribut nismo uključivali u analizu. Razlog za ovakav odabir primjera bio je taj što nas u radu nije zanimala produktivnost određenih upravnih riječi ili atributa. Tada bi bilo presudno imati tačan broj njihovih ponavljanja, što je suština nekih prethodnih analiza registra i imenica (Biber et al. 1999). Nas je zanimala specifičnost značenja koja se ostvaruje u sintagmi sa izvedenom atributivnom imenicom. Stoga su nam različite sintagme bile od presudnog značaja.

Mnogi autori naglašavaju da lista sufiksa koja može da se pronađe u literaturi ponekad ne predstavlja sve sufikse engleskog jezika, pa smo mi za analizu napravili listu kombinujući ponuđene sufikse različitih autora (Bauer 1983; Biber et al. 1999; Plag 2003; Đorđević 2007; Jovanović 2008). U analazu smo na kraju uključili 41 sufiks, ali smo primjere pronašli samo za 25 . Ukupno je pronađeno 678 primjera sintagmi sa izvedenim atributivnim imenicama. Analizu primjera smo podijelili u tri cjeline: analizu izvedenih atributivnih imenica nastalih dodavanjem nastavaka na imenice, pridjeve i glagole, i prije nego što je predstavimo, dajemo tabelarni prikaz brojčanog stanja

4 U daljem radu ćemo nazive datih novina skraćeno navoditi, to jeste TT za The Times, TG za The Guardian, NYT za The New York Times. 
za svaki pronađeni sufiks i za svaku osnovu na koju se sufiks dodao. Tabela pokazuje da je glagolska osnova najučestalija osnova za dodavanje nastavaka sa ukupno 285 pronađenih primjera, dok se na drugom mjestu nalazi pridjevska sa 214 i na trećem imenička sa 179 pronađenih primjera: ${ }^{5}$

\begin{tabular}{|c|c|c|c|c|c|c|c|c|c|c|c|c|c|}
\hline$S$ & క్ & 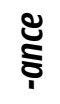 & $\tilde{\mathbf{s}}$ &  & \& & $\vec{\jmath}$ & $\frac{\delta}{\grave{7}}$ & ఫ్ & 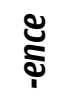 & $\widetilde{\Xi}$ & ఫ & $\vec{\ddagger}$ & $\breve{ఫ}$ \\
\hline I & 4 & 0 & 0 & 0 & 0 & 10 & 1 & 1 & 0 & 0 & 3 & 2 & 2 \\
\hline $\mathbf{P}$ & 0 & 0 & 0 & 0 & 14 & 48 & 6 & 0 & 0 & 0 & 0 & 0 & 0 \\
\hline $\mathbf{G}$ & 8 & 11 & 13 & 1 & 0 & 3 & 0 & 0 & 8 & 16 & 20 & 0 & 0 \\
\hline $\mathbf{U}$ & 12 & 11 & 13 & 1 & 14 & 61 & 7 & 1 & 8 & 16 & 23 & 2 & 2 \\
\hline$S$ & ষ্ণ & న్రి & క్ & $\stackrel{\hbar}{T}$ & $\stackrel{\gtrless}{*}$ & گ్ฐ & 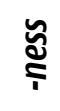 & ఫे & 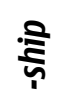 & $\$$ & 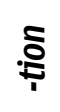 & 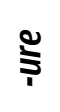 & \\
\hline I & 6 & 0 & 43 & 68 & 0 & 0 & 0 & 3 & 34 & 2 & 0 & 0 & \\
\hline $\mathbf{P}$ & 0 & 0 & 2 & 56 & 42 & 0 & 46 & 0 & 0 & 0 & 0 & 0 & \\
\hline G & 0 & 66 & 0 & 0 & 0 & 71 & 0 & 20 & 5 & 9 & 30 & 4 & \\
\hline $\mathbf{U}$ & 6 & 66 & 45 & 124 & 42 & 71 & 46 & 23 & 39 & 11 & 30 & 4 & \\
\hline
\end{tabular}

Tabela 1. Broj pronađenih primjera u korpusu prema sufiksima koji su upotrebljeni i osnovama na koje su se dodali (S - sufiksi, I - imenička osnova, P - pridjevska osnova, G glagolska osnova i U - ukupan zbir)

\subsection{IZVEDENE ATRIBUTIVNE IMENICE NASTALE OD IMENIČKE OSNOVE I NJIHOVA ZNAČENJA}

U korpusu smo pronašli najviše izvedenih atributivnih imenica koje su nastale dodavanjem sljedećih derivacionih nastavaka na imenice: -ship, -ism, -cy, -ist. ${ }^{6}$ Nastavci -ship i -ism dovode do nastajanja izvedenih imenica koje označavaju neko stanje ili

5 Članke smo analizirali pronalazeći sintagme uz pomoć antcon 3.2.4. koji smo preuzeli na sljedećem sajtu: http://www.antlab.sci.waseda.ac.jp/software.html. Antcon je besplatan softver koji funkcioniše na istom principu kao i mnogi mehanizmi ugrađeni u elektronske korpuse. To znači da jednom kada se unese željeni tekst u ovaj softver, on može na određenu komandu da izlistava željene primjere. Naravno, i ovdje smo većinu primjera morali, nakon izlistavanja, ručno da biramo za analizu jer su nas zanimale samo izvedene imenice $u$ atributivnoj poziciji, a program uglavnom izlistava izvedene imenice ne vodeći računa o funkciji.

6 Iako smo pronašli primjere i sa nastavcima kao što su -dom, -ess, -er, -hood, -age, -ean, -ery, -or i -th, nećemo ih uključiti u diskusiju, jer bi istraživanje izlazilo, po svom obimu, iz okvira ovog rada. A i primjeri sa pomenutim nastavcima pokazali su se kao malobrojniji i uglavnom se radilo o istim imenicama koje su se pojavljivale sa različitim upravnim riječima. Sve pronađene sintagme su ostvarivale različita značenja bez obzira na činjenicu što su atributi bile iste imenice. Pošto smo ta značenja pronašli analizom višebrojnijih sufiksa, odlučili smo da našu diskusiju zadržimo na njima jer smo imali više različitih sintagmi, semantičkih odnosa. Bili smo i u mogućnosti da odgovorimo na pitanje da li oni nude neku čvrstu vezu između forme atributa i značenja sintagme jer nam se činilo da ova malobrojnija grupa negira takvu hipotezu. Takvu praksu ćemo zadržati i pri diskusiji primjera nastalih od pridjevske i glagolske osnove. 
uslove, ali nastavak -ism ujedno dovodi i do nastajanja imenica koja predstavlja nečiji stav ili sistem vrijednosti, neku teoriju (Plag 2003: 114-116). Neki od pronađenih primjera izvedenih atributivnih imenica sa ova dva pomenuta nastavka su?:

(1) He lacks the leadership strength at this point to turn against people... (NYT 7.6)

(2) ..., the school accepted 126 scholarship students out of a class... (NYT 30.6)

(3) ...use of armed drones by the US to kill terrorism suspects was undermining... (NYT 2.6)

(4) ... journalism lecture included other examples of Xinhua's work, notably coverage of ethnic rioting in the far west of China last summer... (TG 6.6)

Značenje navednih sintagmi uklapa se u različite semantičke odnose iako funkciju atributa obavljaju imenice koje, bar posmatrajući značenje koje dobijaju sa nastavcima, dolaze iz iste semantičke grupe. Sintagma leadership strength predstavlja onaj odnos u kom upravna riječ strength postoji, tj. koristi se kako bi se svrha atributivne imenice leadership upotpunila (svrha), što, u stvari, znači 'strength needed or used for leadership'. $S$ druge strane, sintagma scholarship students ostvaruje odnos koji zovemo objekatski tip 2 jer se radi o studentima koji su objekat procesa stipendiranja. Ova sintagma može da ima još jedno dopunsko značenje, a to je značenje subjekatskog tipa 2 jer studenti mogu da budu osobe koje primaju stipendiju. Izvedena imenica terrorism označava aktivnost, a sintagma u kojoj vrši funkciju atributa ima značenje koje zovemo specijalizacija jer pomenuta aktivnost određuje zanimanje, odnosno specijalističko polje djelovanja za upravnu riječ suspects. Sintagma journalism lecture ostvaruje značenje sadržaja jer se radi o predavanju koje govori o novinarstvu, tj. upravna riječ se bavi atributivnom imenicom.

$\mathrm{U}$ radu smo pronašli imenice izvedene nastavcima -ist i -cy. Nastavkom -ist nastaje imenica koja ima sljedeće značenje: „osoba koja se bavi onim što predstavlja imenica koja je osnova", dok nastavak -cy označava stanja, osobine, kvalitete, činjenice ili uz metaforičko interpretiranje i instituciju (Plag 2003: 110-115). Većina izvedenih imenica sa sufiksom -cy dovodi u najvećem broju primjera do značenja svrhe (6). Da nije uvijek tako, pokazuje sintagma agency journalist, gdje imamo značenje lokacijskog tipa 1 jer imamo novinara iz agencije, tj. porijeklo, a lokacija upravne riječi se predstavlja atributom. Ova sintagma, međutim, može da ima i još jedno značenje, a to je specijalizacija jer je ujedno reč i o agencijskom novinaru, što znači da je atribut predstavio specijalističko polje za upravnu riječ:

(5) ... agency journalist, attributes the rise of the princelings to... (TT 4.6)

(6) ... a politician tried to stop a rival from filing candidacy papers. (NYT 13.4)

U korpusu su pronađeni i primjeri sintagmi sa atributivnom imenicom na -ist, ali nastavak je dovodio do najrazličitijih značenja. Izdvajamo samo dva primjera:

(7) ... financial analyst came to join a terrorist network in the mountains...(NYT22.6)

(8) ... Mr. Shahzad began dabbling in jihadist ideology, listening to... (NYT 22.6)

7 U radu ćemo navoditi samo nekoliko primjera za svaki nastavak jer bi navođenje svih pronađenih primjera izašlo iz okvira ovog rada. 
Značenje koje se formira u sintagmi terrorist network jeste značenje sadržaja jer je mreža sastavljena od terorista, ali kao dopunsko značenje može da se navede i subjekatski tip 1 jer teroristi mogu da formiraju mrežu, a fraza jihadist ideology svoje značenje može da predstavi tek kroz parafraziranje (ideology founded and shared by jihadists).

\subsection{IZVEDENE ATRIBUTIVNE IMENICE NASTALE OD PRIDJEVSKE OSNOVE I NJIHOVA ZNACEENJA}

Derivacioni nastavci koji, vežući se za pridjevsku osnovu, dovode do nastajanja imenica obično dovode do nastajanja pojmova koji označavaju kvalitet (-ness), stanje ili svojstva (-ity), osobe (-ist), stanja, osobine, kvalitete, činjenice ili, uz metaforičko interpretiranje, i instituciju (-cy/-ce) (Plag 2003: 115-116). ${ }^{8}$

Svi pronađeni primjeri izvedenih imenica koje imaju nastavak -ness izražavaju neku vrstu kvaliteta, pa onda i ne čudi što sa upravnom riječju u sintagmi formiraju odnos koji zovemo svrha. Poenta ovakvog odnosa jeste da upravna riječ služi ili se koristi u svrhu atributivne imenice, što u našim primjerima konkretno znači postizanje ili očuvanje određenog kvaliteta:

(9) ..., with an airworthiness certificate and the registration plate N878 UP. (TG 28.5)

(10) ... learning mindfulness skills is associated with greater, sustained... (TG 21.5)

Da to ne mora nužno da bude i jedino značenje, pokazuje sintagma airworthiness certificate koja ostvaruje i značenje sadržaja - 'certificate which attests that some aircraft is airworthy'.

Pronađeni primjeri sa nastavkom -ity ostvaruju sa upravnom riječju u sintagmi dva značenja: sadržaj i svrhu. To znači da se upravna riječ bavi pojmom koji je predstavljen atributivnom imenicom, ali i postoji zbog tog pojma:

(11) ..., officials said, and security measures will remain in place... (TT 17.6)

(12) Taylor says calling Campbell would be a publicity stunt and, of course, he is right to worry for her. (TG 5.6)

Pronađeni primjeri imenica izvedenih nastavkom -ist označavaju osobu, a sa upravnom riječju formiraju, pored mnogih drugih značenja, ili odnos koji ne možemo precizno da svrstamo ni u jedan semantički šablon (leanings associated with separatist) (13) ili značenje sadržaja i svrhe $(14,15)$ :

(13) A wealthy lawyer who makes no secret of his separatist leanings,... (TG 11.4)

(14) Her husband Horst Rosenkranz, 67, publishes an extremist magazine and raises funds... (TT 18.4)

8 Pronašli smo takođe i primjere izvedenih atributivnih imenica sa sljedećim nastavcima (naravno u mnogo manjem broju nego ove o kojima diskutujemo): -dom i -ism. 
(15) Spires said it was a milestone for environmental and other activist groups in the Amazon (TG 13.4)

Pokazalo se da primjeri izvedenih atributivnih imenica sa nastavcima -ce/-cy ostvaruju najrazličitije odnose sa upravnom riječju sintagme, pa čak i kada se radi 0 istim atributima, što nam je bilo interesantno za diskusiju. Neki od pronađenih primjera to pokazuju:

(16) It declared a ceasefire in 2006 but reverted to violence months after peace talks with the government (TG 20.5)

(17) Intelligence officials say that drone strikes are the most effective weapon in the fight against al-Qaeda. (TT 2.6)

(18) The intelligence team did not know Faisal Shahzad, an American of Pakistani descent... (TT 5.5)

(19) He has ordered the police and the intelligence services to investigate... (TT 5.6)

I dok značenje sintagme violence months dobijamo tek kroz parafraziranje (months filled with violence), sintagme $s$ istom atributivnom imenicom ostvaruju najrazličitije semantičke odnose sa upravnom riječju: specijalizacija (intelligence officials), dio i svrha (intelligence team, intelligence services) jer su timovi i službe dio obavještajnog sistema, ali je ujedno njihova svrha da se bave obavještajnim aktivnostima.

(20) China's Ministry of Public Security issued an emergency notice... (TT 4.6)

(21) Heavily armed police and emergency vehicles shut down some of... (TT 2.5)

(22) ... early defeat for Britain's new government over the introduction of transparency standards for hedge funds. (TG 17.5)

Većina fraza sa izvedenom imenicom na -cy ostvaruje značenje svrhe, što ne čudi. Naime, nastavak dovodi do nastajanja imenice koja označava određene kvalitete, činjenice, stanja koja postaju osnovna svrha za upravnu riječ, pa tako imamo obavještenje koje se izdaje u slučaju opasnosti (20), vozila koja se koriste u slučaju opasnosti (21) ili standarde u svrhu transparentnosti, mada bi posljednja sintagma mogla da ima i jedno dopunsko značenje, a to je značenje sadržaja jer standardi mogu i da govore o transparentnosti.

\subsection{IZVEDENE ATRIBUTIVNE IMENICE NASTALE OD GLAGOLSKE OSNOVE I NJIHOVA ZNACENJA}

Najveći broj primjera izvedenih atributivnih imenica u našem korpusu nastao je dodavanjem sljedećih nastavaka na glagolsku osnovu: -ion, -tion, -er/-or, -ment, -ant/-ent. ${ }^{9}$

Našu diskusiju započinjemo sa nastavkom -ion koji označava ili neki događaj ili rezultate nekog procesa (Plag 2003: 114). Izvedene atributivne imenice koje su

9 Pronašli smo takođe i primjere izvedenih atributivnih imenica sa sljedećim nastavcima (naravno u mnogo manjem broju nego ove o kojima diskutujemo): -ance, -ence, -age, -ation, -cy, -ship, -ure, -th. 
nastale dodavanjem nastavka -ion ostvaruju različite semantičke odnose sa upravnom riječju; od odnosa institucije, gdje upravna riječ, zajedno sa atributivnom imenicom, predstavlja djelatnost neke institucije (23) do odnosa koje zovemo sadržaj (24) i svrha (25), pa čak i do oba odnosa (sadržaj i svrha) u jednoj sintagmi (26):

(23) .. Mr. Coke's influence seemed to grow and his business interests, including an entertainment company and a construction company,... (NYT 22.6)

(24) ... José Miguel Insulza, told reporters on Thursday that allowing Mr. Zelaya to return to Honduras, where he now faces corruption charges,... (NYT 5.6)

(25) In order to allow more reconstruction materials in to repair infrastructure and homes destroyed in... (TT 17.6)

(26) ..., did not contest a prosecution request that he remain in custody. (TT 19.5)

Uvijek je interesantno posmatrati istu atributivnu imenicu sa različitim upravnim riječima, a posebno ukoliko dolazi do nastajanja najrazličitijih semantičkih odnosa. Upravo takav je slučaj sa -tion imenicama gdje sintagma sa imenicom pollution ima značenje sadržaja (27), svrhe (28) i lokacijskog tipa 2 (29). Navodimo još jedan primjer značenja svrhe i sadržaja koji se istovremeno ostvaruju u posljednjoj sintagmi (30) u kojoj imamo drugu atrubutivnu imenicu izvedenu na isti način:

(27) Deepwater Horizon oil rig sinks, sparking pollution fears. (TG 23.4)

(28) ... many have been progressively retrofitted with new pollution filters, though few produce both heat and power... (NYT 13.4)

(29) ... the Environmental Protection Agency is monitoring pollution levels. (TT 8.6)

(30) .... intervention team came to rescue his yacht, the Tanit,... (TG 30.5)

Izvedene imenice koje su nastale dodavanjem nastavka -ment, označavajući pri tom proces ili rezultat neke radnje, u sintagmama ostvaruju različite semantičke veze. Neki od pronađenih primjera su:

(31) ..., Mr. Coke's influence seemed to grow and his business interests, including an entertainment company and a construction company,... (NYT 22.6)

(32) Media experts say Japan has yet to see such critical questioning of its establishment press. (NYT 20.6)

Sintagma entertainment company, kao i većina sintagmi u kojoj imenice koje označavaju neki viši stepen udruživanja koji se postiže u grupama, organizacijama, industrijama itd. vrše funkciju upravne riječi, ima značenje institucije i atributivna imenica samo određuje čime se ta institucija tačno bavi (entertainment). Kada sintagma ima značenje identiteta, kao što je to slučaj sa sljedećom navedenom sintagmom (establishment press), onda se i atributivna imenica i upravna riječ odnose na isti pojam, i tako se objedinjuju dva pojma u jedan (not any kind of press, but establishment press).

Za kraj ostavljamo nastavke -er/-or i -ant/-ent. Nastavci -er/-or mogu da imaju više značenja, ali ipak značenje koje objedinjuje sva jeste značenje osobe koja se bavi onim što se označava osnovom ili značenje stvari koja se odnosi na ono što se označava 
osnovom (worker, investor), a koja ne mora nužno da bude glagolska (Plag 2003: 112). Neki od pronađenih primjera su:

(33) The laws, enacted in 2008, were intended to channel worker frustrations through a system of arbitration and courts... (NYT 20.6)

(34) ... has heightened investor anxiety over whether the new government... (TG 4.6)

Značenje sintagmi worker frustrations i investor anxiety je subjekatski tip 1. 0vo značenje po svojoj semantičkoj strukturi dosta podsjeća na rečenice gdje su atributivne imenice subjekti aktivnosti koju predstavljaju upravne riječi. Značenje ovih sintagmi bilo bi mnogo jednostavnije za one koji treba da shvate poruku kada bismo atributivne imenice upotrijebili u množini, npr. workers frustrations, investors anxiety. U tom slučaju bi značenje atributivnih imenica u množini jasno pokazivalo da se problemi koji se predstavljaju upravnim riječima (frustrations, anxiety) odnose na sve radnike ili na sve investitore, a ne na jednog (Quirk et al. 1985: 1334). Razlog zašto upotreba atributivnih imenica u množini postaje sve učestalija jeste taj što se na taj način zadržava ekonomičnost izraza, a ujedno izbjegava višeznačnost (Biber et al. 1999: 595).

Nastavci -ant/-ent obično dovode do nastajanja imenica koje označavaju osobe (Plag 2003: 110; Bibet et al. 1999: 321), ali i pokazuju i najrazličitije semantičke odnose sa upravnom riječju sintagme, kao što su vrijeme (35), subjekatski tip 1 (36) ili identitet $(37,38)$ :

(35) ... who met Maclean to discuss his student dissertation in 1978. (TG 8.6)

(36) ... "Just look at the way student elections were going before... (TG 10.6)

(37) A consultant psychiatrist at Butabika hospital,... (TG 19.5)

(38) ..., leaving no Protestant voice on the court for the first time. (TT 10.5)

\section{ZAKLJUČAK}

Svjesni činjenice da atributivne imenice, bez obzira na svoju morfološku strukturu ostvaruju različite odnose sa upravnom riječju u sintagmi, željeli smo da te odnose otkrijemo i utvrdimo koliko njihovo razumijevanje morfološka struktura može da olakša ili oteža. Da bismo mogli da interpretiramo značenje sintagme, prvo smo morali da znamo značenje izvedene imenice. Mislili smo da će taj dio posla možda biti lakši jer derivacioni nastavci usmjeravaju značenje izvedene imenice ka već određenom semantičkom šablonu, ali na kraju smo zaključili da mali broj izvedenih imenica sa istim nastavkom vodi ka istom odnosu sa upravnom riječju u sintagmi. Tako, na primjer, nastavak -ship dovodi do nastajanja imenica koja označava neko stanje, aktivnosti ili uslove, ali u korpsu ostvaruju najrazličitija značenja: svrha (leadership strength) ili objekatiski tip 2/subjekatski tip 2 (scholarship students). Posebno je interesantno bilo analizirati sintagme u kojima se na poziciji atributa pojavljuje ista izvedena imenica i zaključiti da ona sa različitim upravnim riječima ostvaruje različita značenja kao što je bio slučaj sa, na primjer, imenicom pollution koja je ostvarila značenje sadražaja 
(pollution fears), svrhe (pollution filters) ili lolacijskog tipa 2 (pollution levels). Rijetke su sintagme u kojima se formira isto značenje kada se pojave isti derivacioni nastavci. Takvi su jedino svi primjeri sa nastavkom -ity koji formiraju odnos sadržaja i svrhe sa upravnom riječju (publicity stunt, security measures). U određenom broju slučajeva isti nastavak nam nije mogao pomoći da smjestimo značenje sintagme u neki od ponuđenih semanatičkih šablona, pa smo značenje dobijali tek kada cjelokupnu sintagmu parafraziramo, a prije toga se naravno osvrnemo na kontekst u kojem se pojavljuje (jihadist ideology, separatist leanings).

$\mathrm{Na}$ kraju možemo da zaključimo da je naša početna hipoteza bila ispravna i kroz rad se i potvrdila. Izvedene imenice ostvaruju najrazličitije odnose sa upravnom riječju, što se može tvrditi i za ostale vrste imenica u engleskom jeziku. Ponekad, ali u jako malom broju primjera, sufiks može da nam pomogne i da nas odmah uputi ka jednom značenju, ali u mnogo većem broju primjera isti sufiks, pa čak i iste imenice sa različitim upravnim riječima su nam otkrivale širok spektar različitih značenja koja su se formirala u zavisnositi od konteksta. To samo potvrđuje nepostojanje veze između morfološke strukture izvedenih atributivnih imenica i značenja imeničke sintagme i dokazuje svu delikatnost i složenost interpretiranja značenja sintagme sa atributivnim imenicama.

\section{LITERATURA}

Bauer, L. 1983. English Word-formation. Cambridge: Cambridge University Press.

Baugh, A. C. i T. Cable. 2002. A History of the English Language. London: Roultledge.

Biber, D. 2006. University Language - A corpus-based study of spoken and written registers. Amsterdam/Philadelphia: John Benjamins Publishing Company.

Biber, D. et al. 1999. Longman Grammar of Spoken and Written English. Harlow: Pearson Education Limited.

Blaganje, D. i I. Konte 1979. Modern English Grammar. Ljubljana: Državna založba Slovenije.

Đorđević, R. 2007. Gramatika engleskog jezika. Četvrto izdanje. Beograd: Čigoja štampa. Jovanović, V. Ž. 2008. English Morphology. A Coursebook. Niš: Filozofski fakultet Niš. Plag, I. 2003. Word-Formation in English. Cambridge: Cambridge University Press.

Quirk, R. et al. 1985. A Comprehensive Grammar of the English Language. Harlow: Longman Group Limited.

Жарковић, М. 2012. Атрибутивне именице исемантички односи сауправном ријечју именичке фразе. У М. Ковачевић (ур.) Радови Филозофског факултета XIV/1. Пале: Филозофски факултет Универзитета у Источном Сарајеву, 327-336. 


\section{SUMMARY}

\section{MORPHOLOGICAL STRUCTURE OF DERIVED PREMODIFYING NOUNS AND SEMANTIC RELATIONS WITH NOUN PHRASE HEAD IN CONTEMPORARY ENGLISH}

Derived nouns are formed by means of derivational suffixes attached to nouns, adjectives and verbs. It is a well-known fact that derivational suffiixes guide the meaning of the derived noun toward already determined semantic patterns. Guided by the known fact that premodifying nouns bring dense packaging of information into the phrase structure, not always easy to interpret, the main aim was to see how much morphological structure of derived premodifying nouns can infulence the guidance and eventually interpretation of the information. In the end, after descriptive and analytic analysis of examples taken from the newspaper register, we conclude that derived nouns express the most versatile meaning-relationships with the phrase head and that morphological structure does not greatly influence guidance and final interpretation of those meaning-relationships. Some of these meaning-relationships can be predicted due to used derivational suffixes because they always lead to the same phrase meaning-relationships, but in many examples the same suffix did not lead to the creation of the same meaning-relationship which only confirmed how delicate interpreting noun phrase with premodifying nouns can be.

KEYWORDS: noun, noun phrase, morphological classification, semantic relations.

(Originalni naučni rad primljen 08.06.2014;

ispravljen 27.11.2014;

prihvaćen 16.12.2014) 